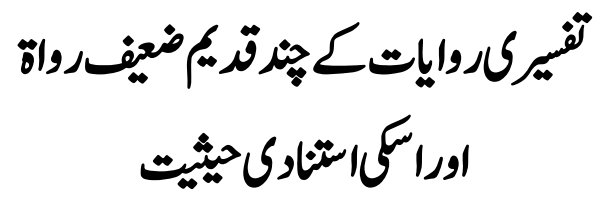

\title{
Some "ضعيف" (weak) Commentators of Quran of the early ages and the nature of their referential authenticity
}

$$
\text { *ثبان نورين }
$$

\section{Abstract}

Just after the sad demise of Prophet his companion's initiated using a very cautious behavior in writing the commentaries of "Quran". They would present only those commentaries of "Quran" which they would listen from the Prophet either directly or indirectly; or they would have seen the circumstances of the revelation of a verse by themselves in person or that which would have dawned upon them by the way of a verdict and derivation. However, the commentators of the later eras did not take into consideration this cautiousness. Due to this very reason, all those Quran and Sunna's commentary related traditions reported from them, a great amount of weakness is found in the same. This weakness, causes a great defect in the comprehension of (religion). Consequently, the "ائمـ of the critical study of the Hadith etc while criticizing it, have not only disclosed their weakness but rather they have added a term of " weak Hadith narrators and untrustworthy narrators in the Islamic "ائمجرح وتعديل" literature. In this Article, a critical review of the sayings of the having deliberated on the authenticity of the references of the commentators of the early ages (of Islam), is being presented.

Key Words: Commentaries, Revelation, Verdict, Narrators.

$$
\begin{aligned}
& \text { تضمك لنوكواصطال منهوم }
\end{aligned}
$$

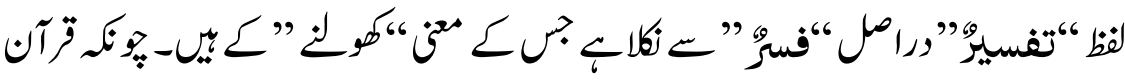

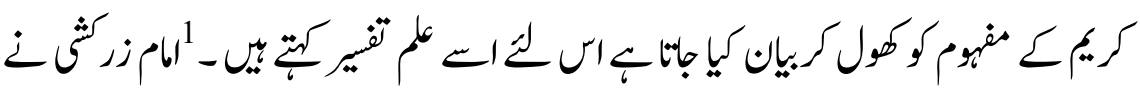

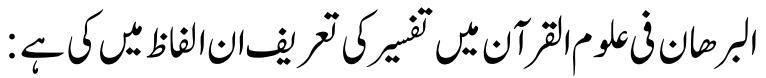

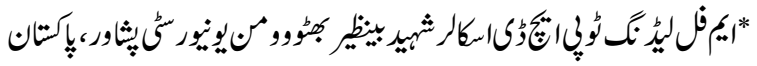

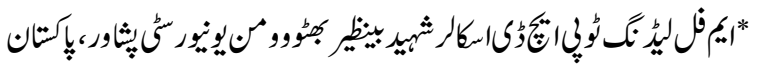




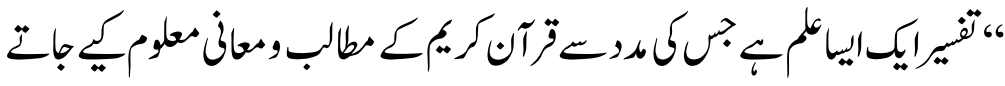

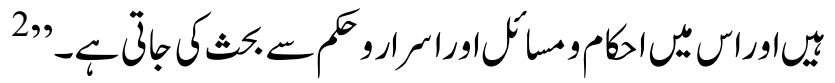

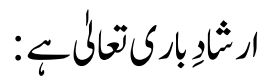

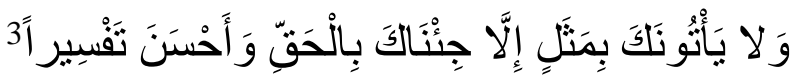

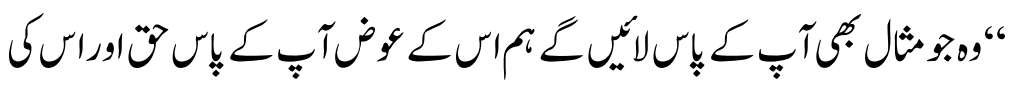

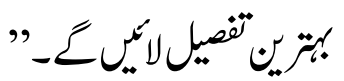

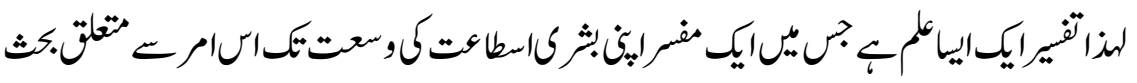

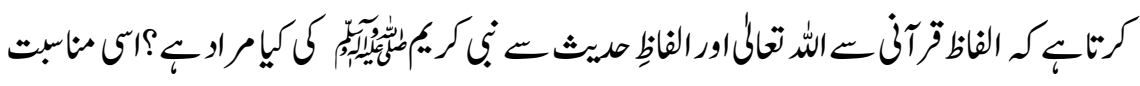

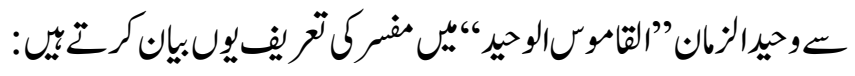

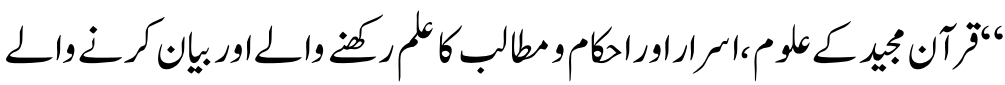

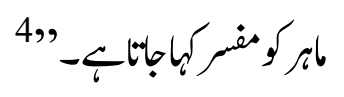

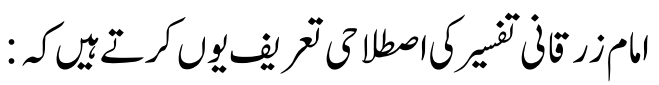

و التفسير في الاصطلاح: علم يبحث فيه عن القر آن الكريم من

حيث دلالته على مر اد الله تعالى بقدر الطاقة البشرية. 5

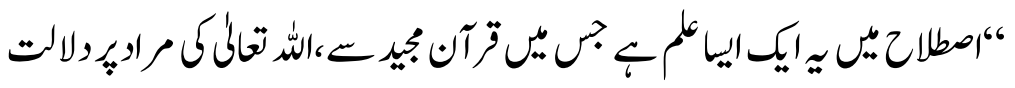

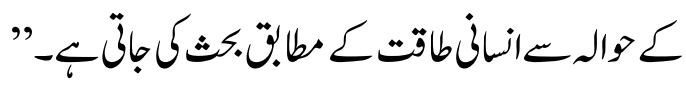

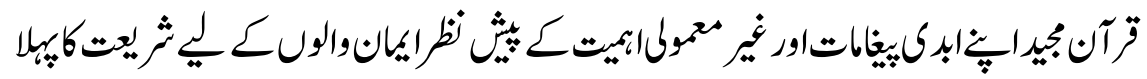

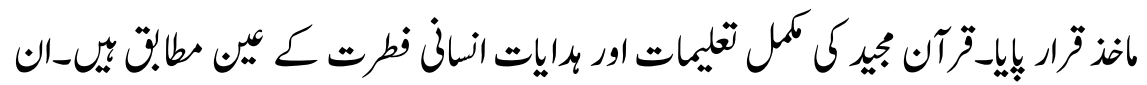

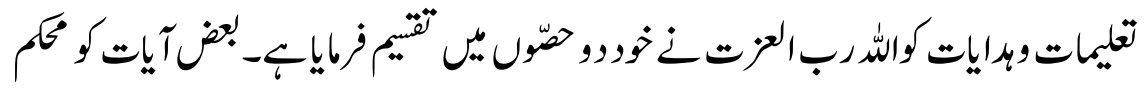

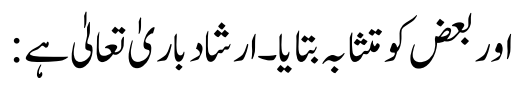




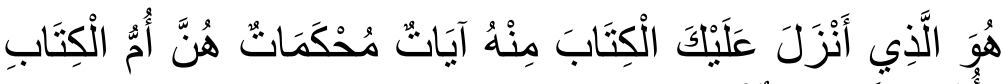

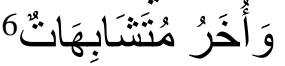

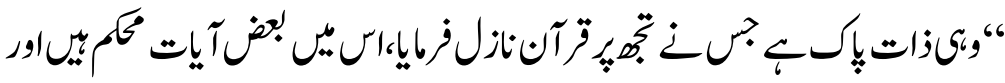

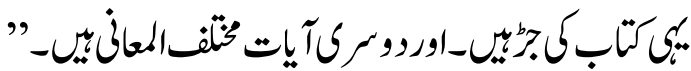

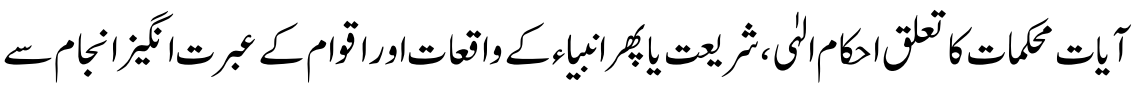

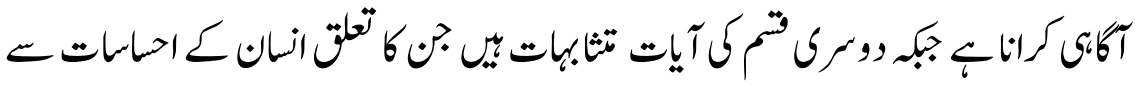

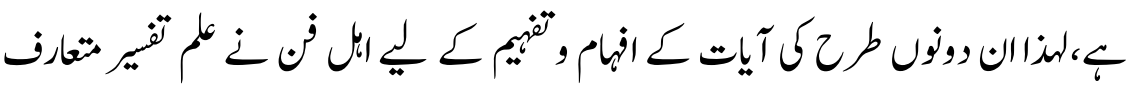

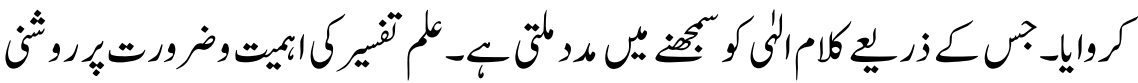

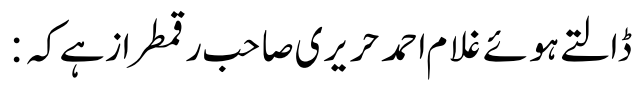

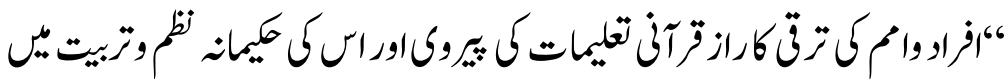

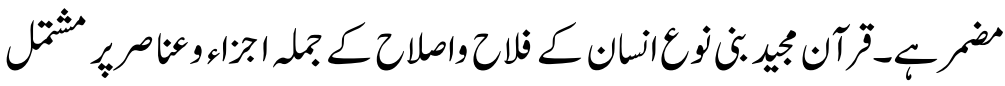

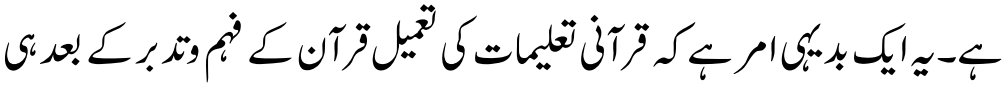

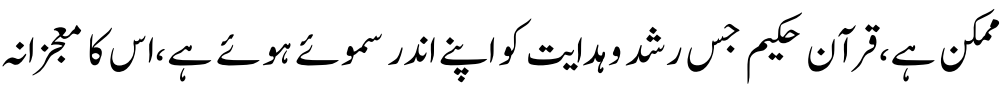

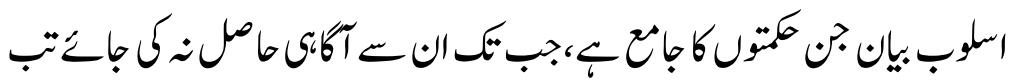

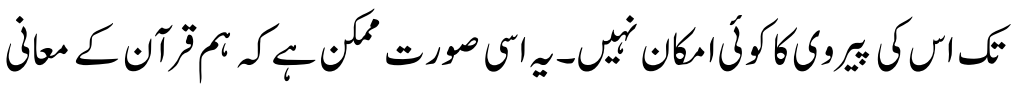

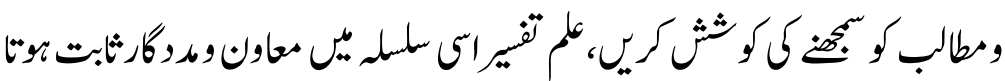
$7 \%-c$

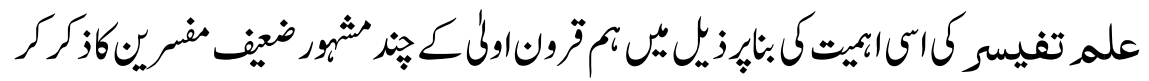

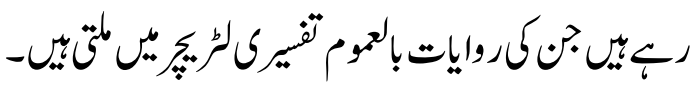
مقاتلك.ن سيمان

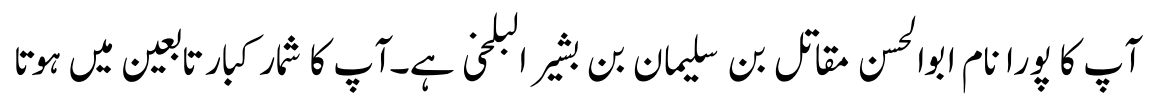

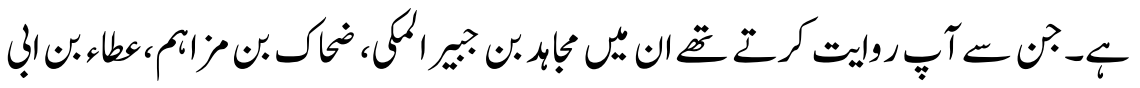




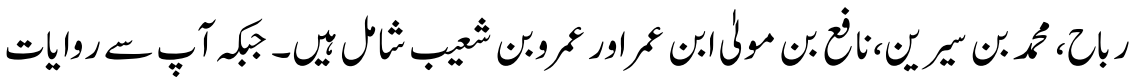

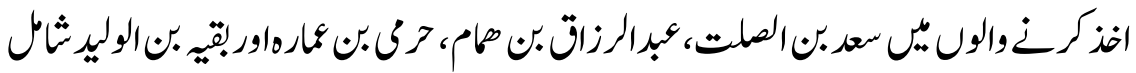

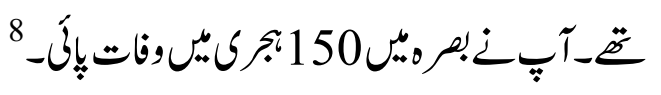

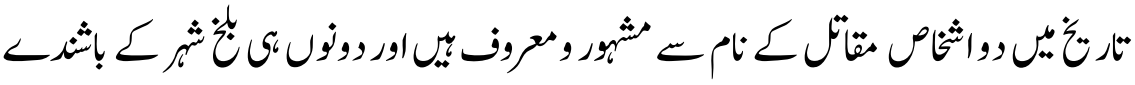


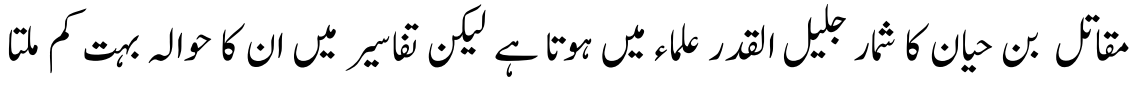

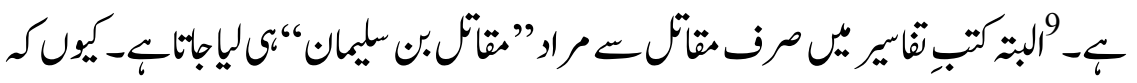

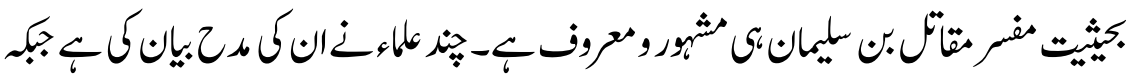

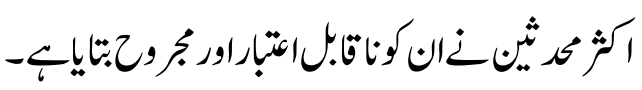

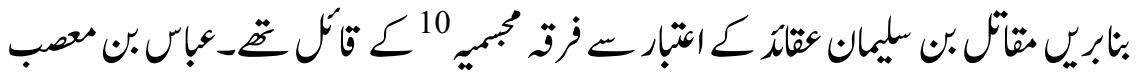

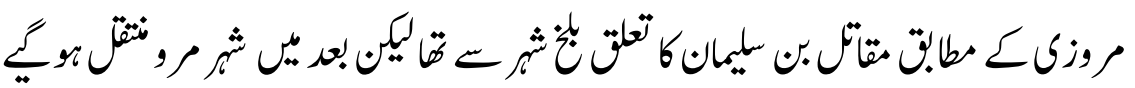

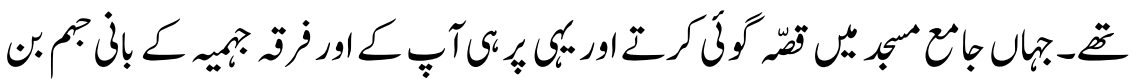

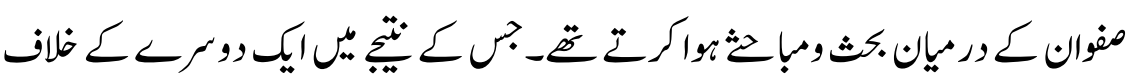

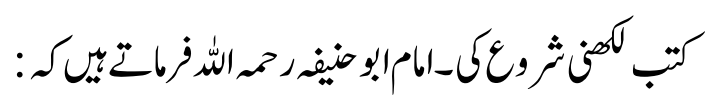

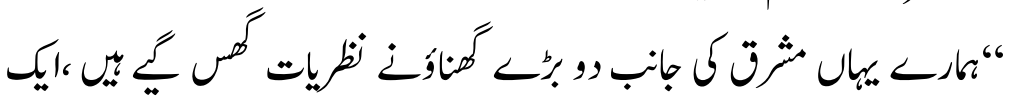

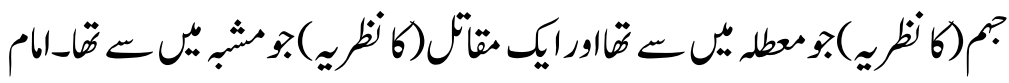

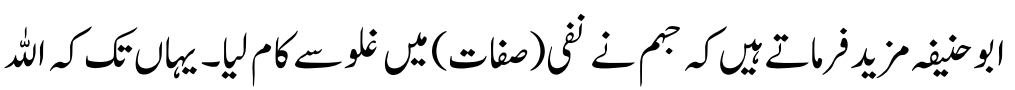

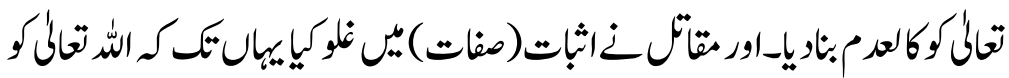

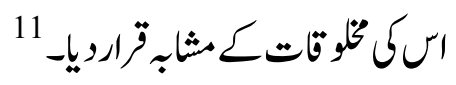

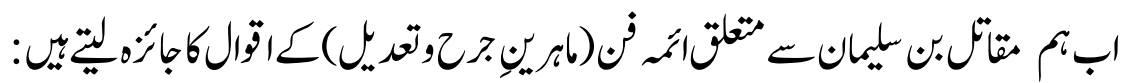

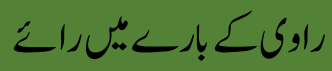

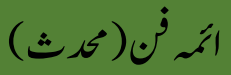

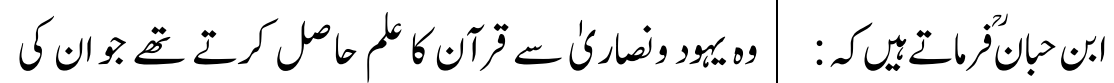




\begin{tabular}{|c|c|}
\hline كتّلونك موانت 12 & \\
\hline 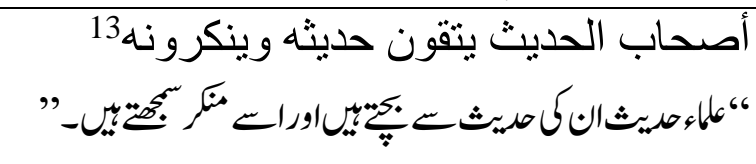 & 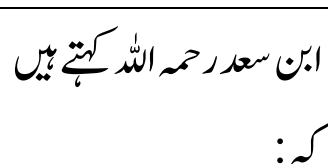 \\
\hline 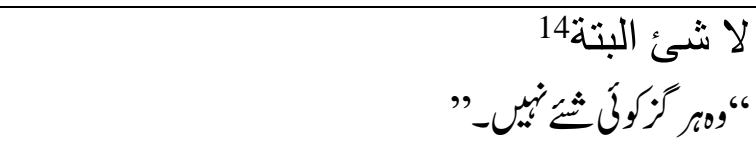 & بقول|ام مخاركر حمـ الضّ \\
\hline 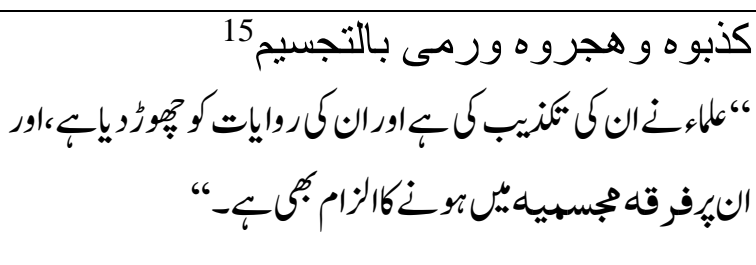 & 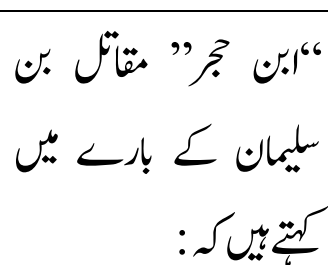 \\
\hline
\end{tabular}

\section{عطيم.ن معد.نجنارة}

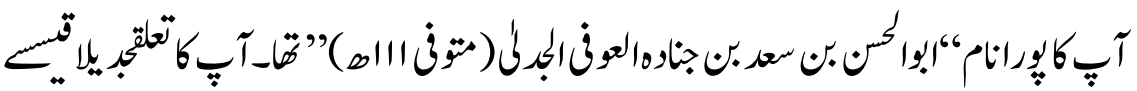

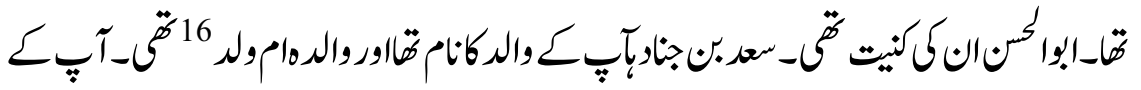

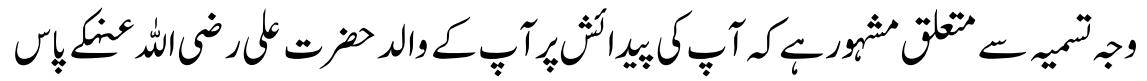

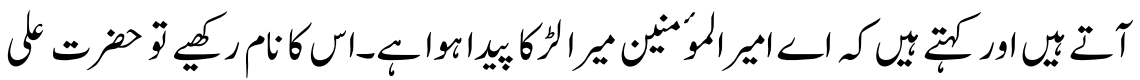

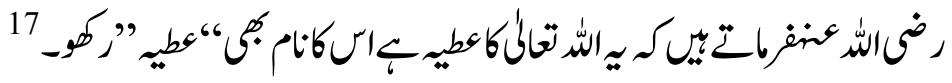

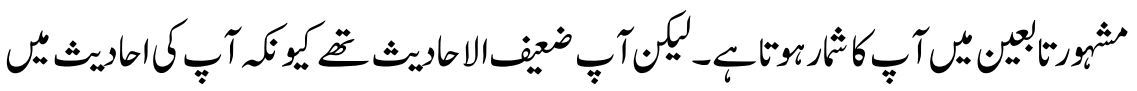

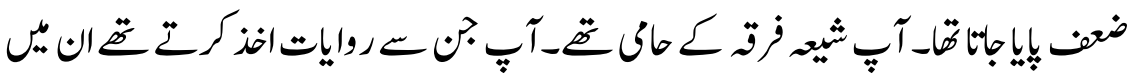

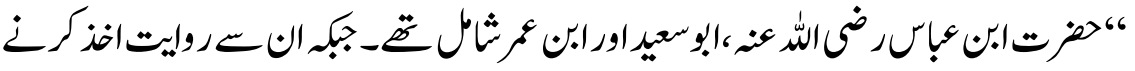

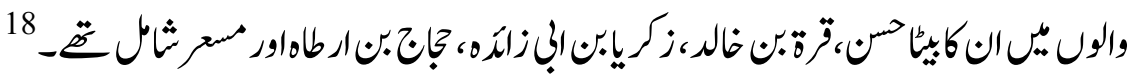

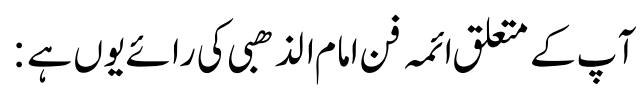

تَابِعِيّ مَتَثْهُور مجمع على ضعفه 19

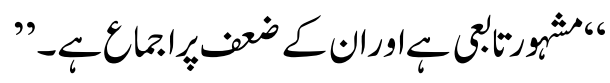




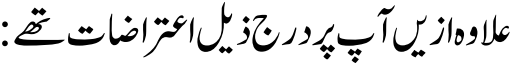

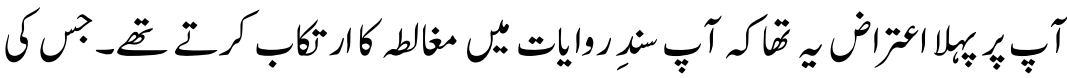

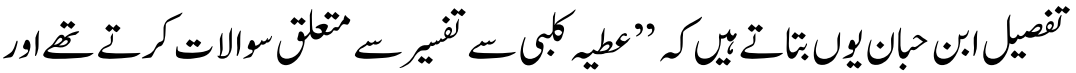

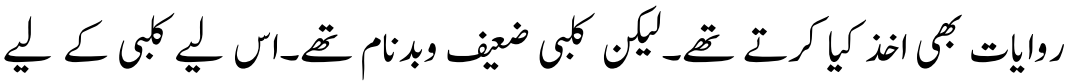

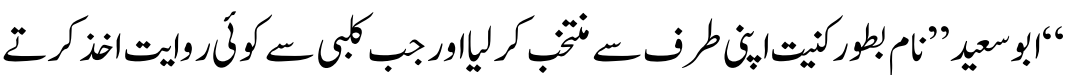

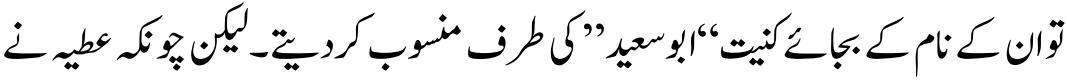

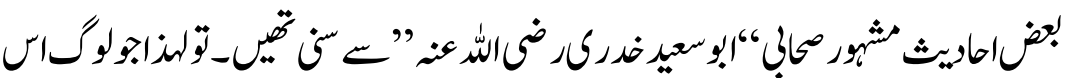

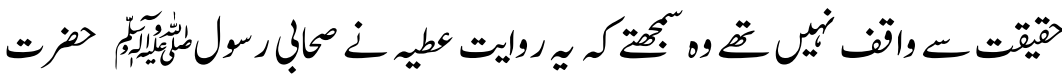

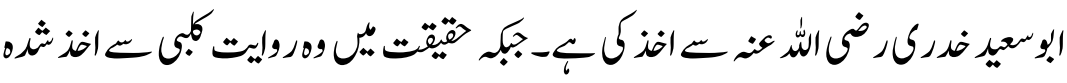

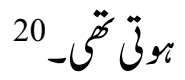

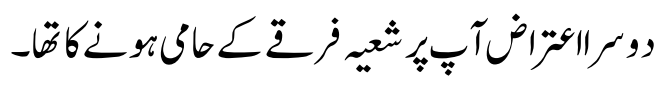

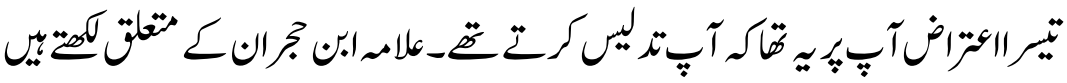

\section{صلوقي يخطئ كثيراً، كانشيعيامسلساً}

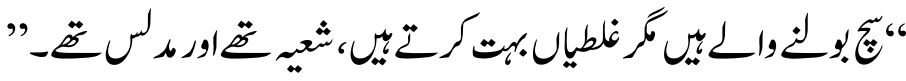
رنج.نانى

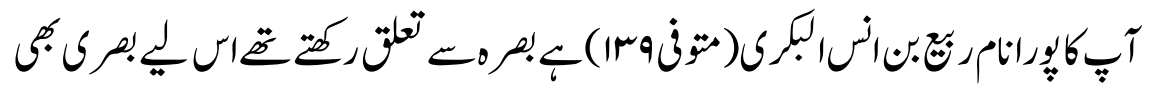

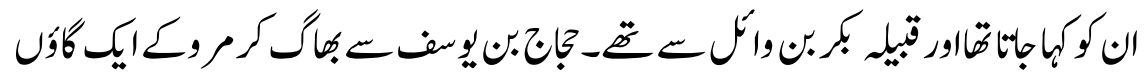

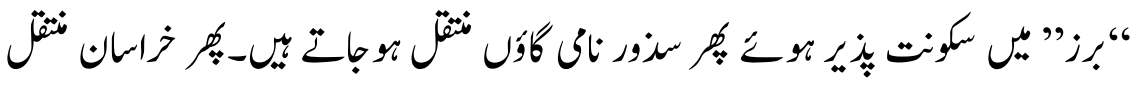

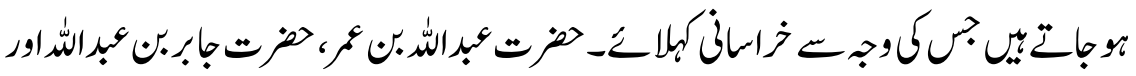

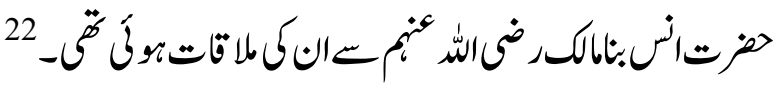




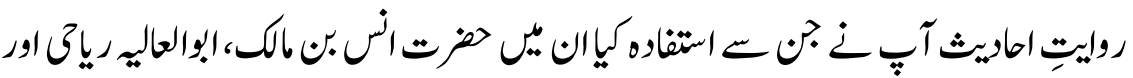

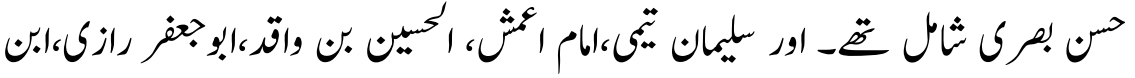

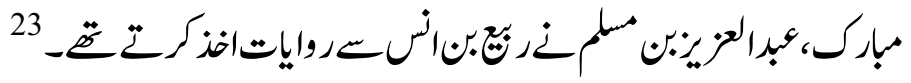

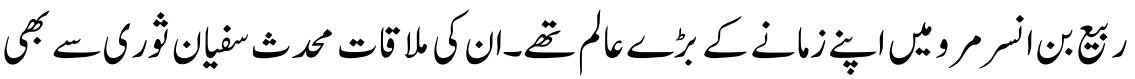

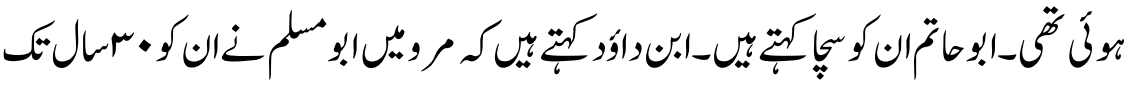

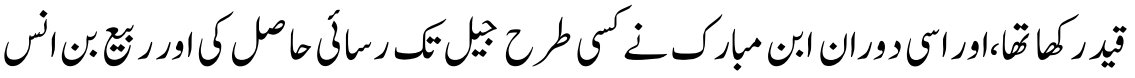

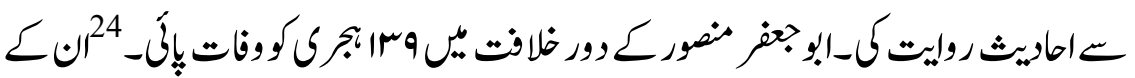

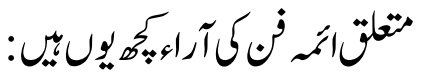

\begin{tabular}{|c|c|}
\hline 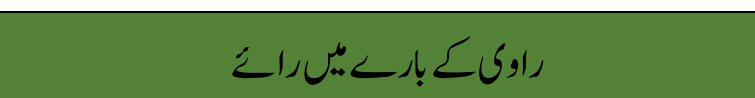 & ايمـ فُ(محث) \\
\hline 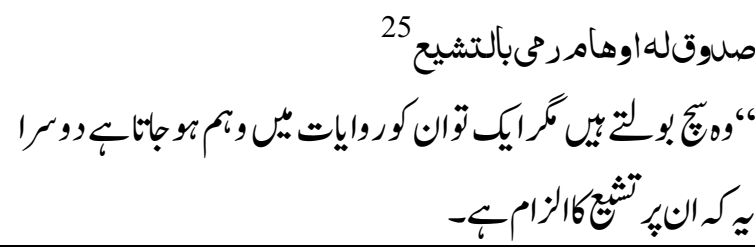 & 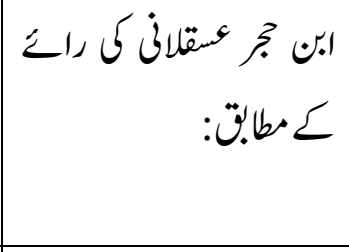 \\
\hline 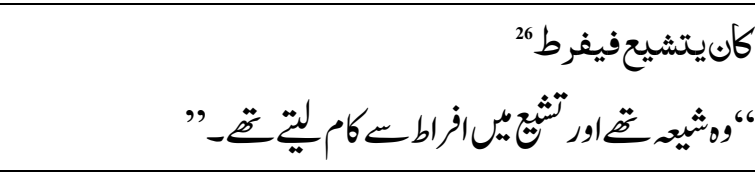 & 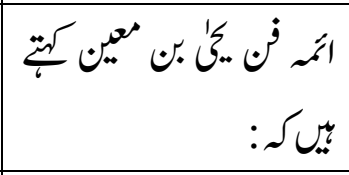 \\
\hline 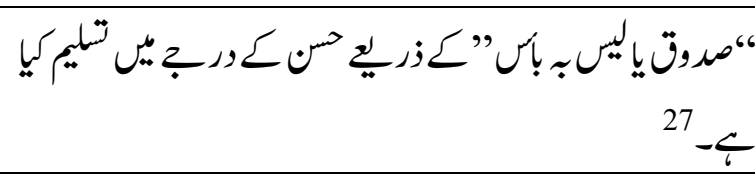 & 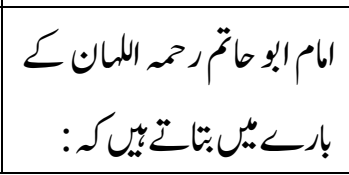 \\
\hline
\end{tabular}
الوالمرمكُنالائب

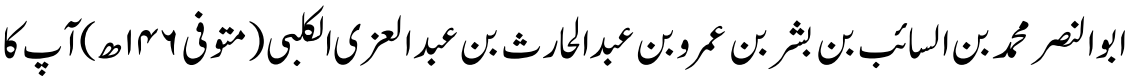

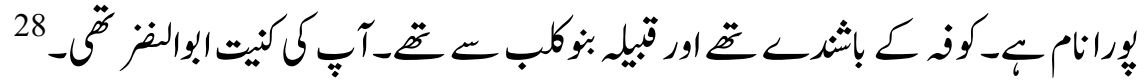

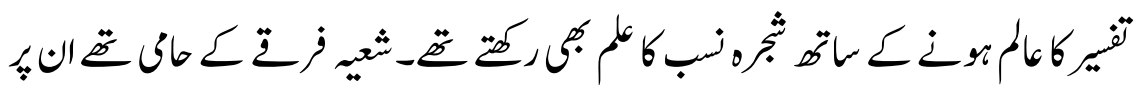

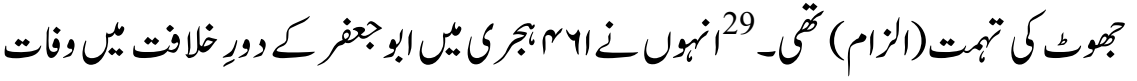

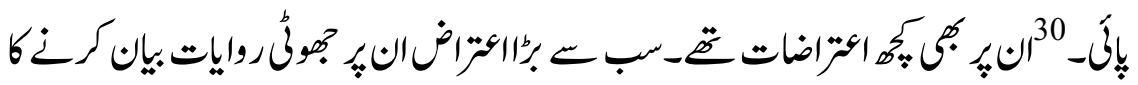

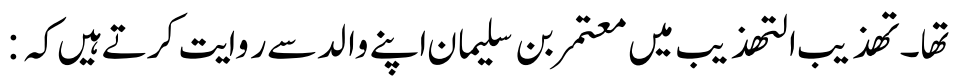




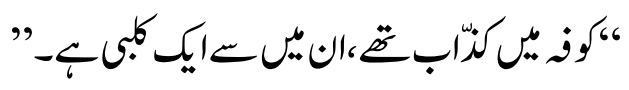

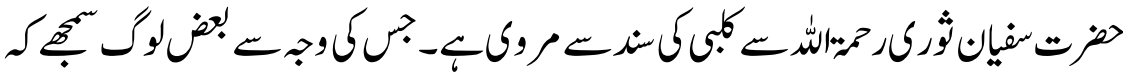

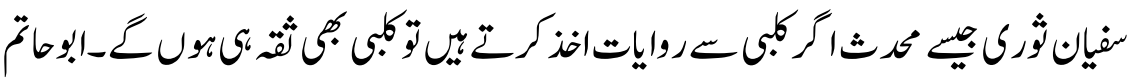

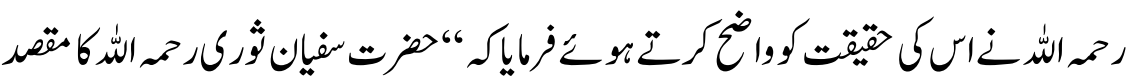

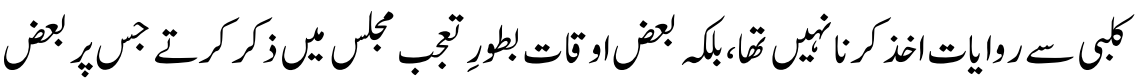

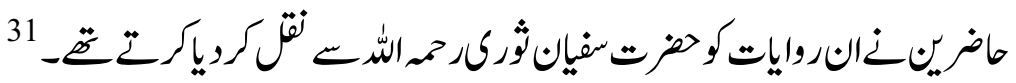

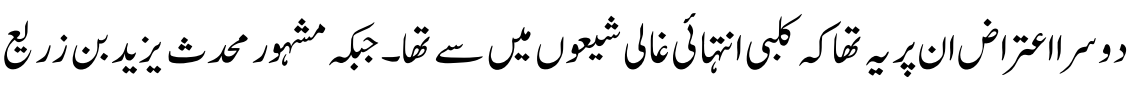

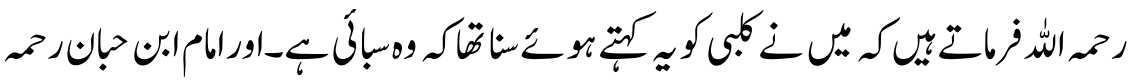

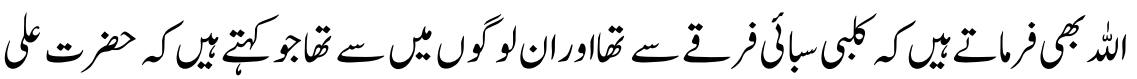

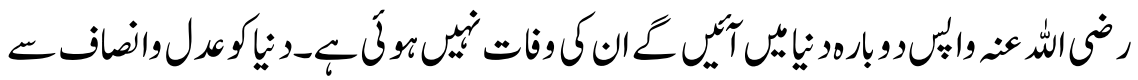

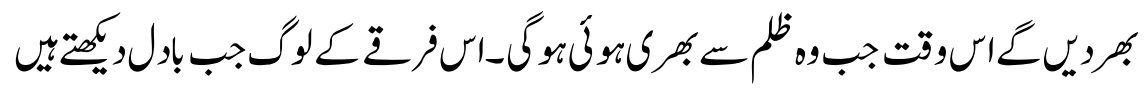

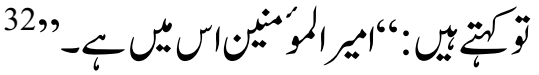

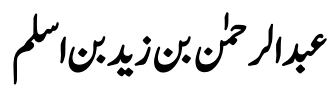

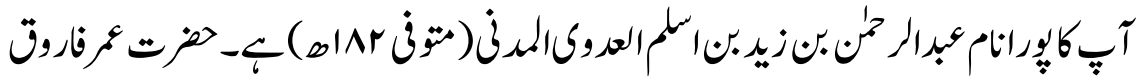

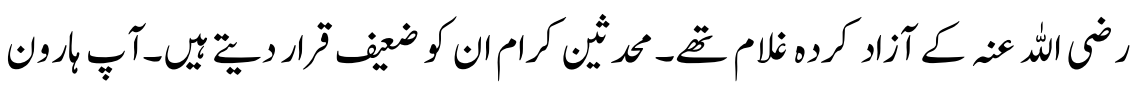

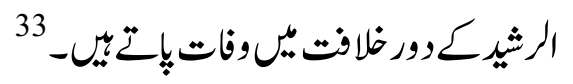

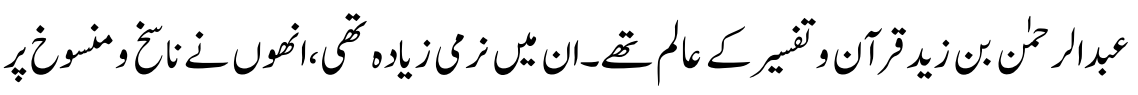

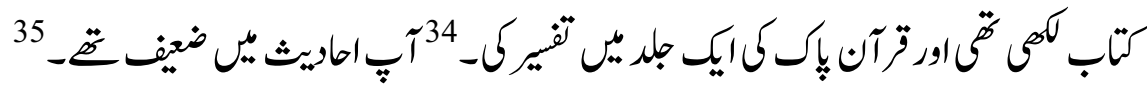

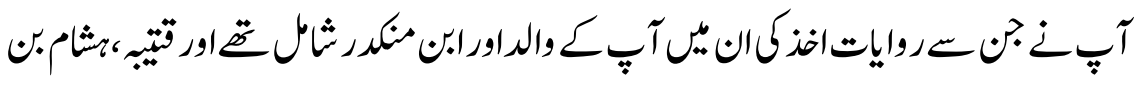

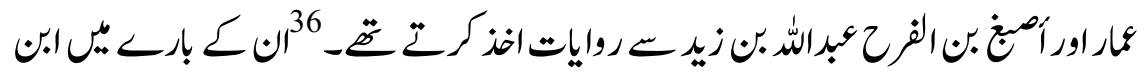
جوزكر حم اللَكمنيّكم:

\section{اجعوا على ضعفه 37}




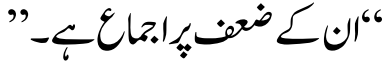

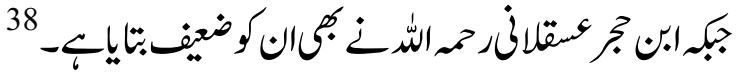

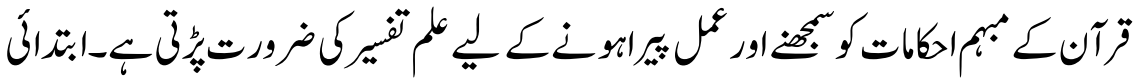

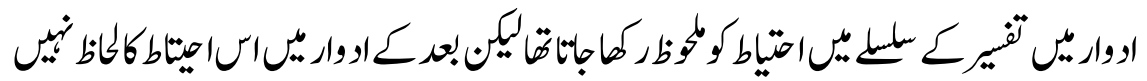

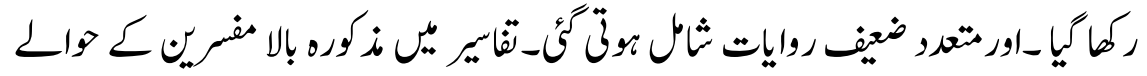

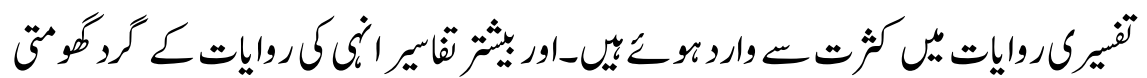

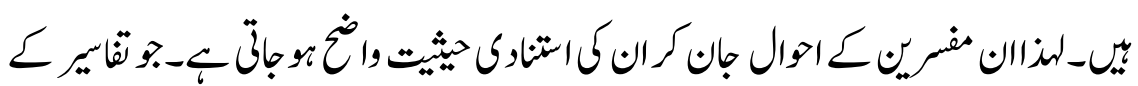

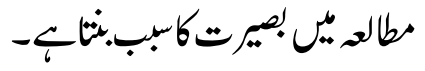

\section{هاثّى حواله جات}

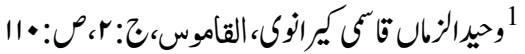

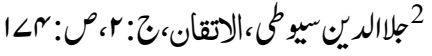

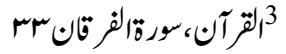

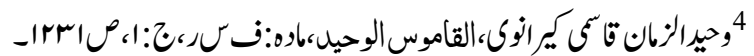

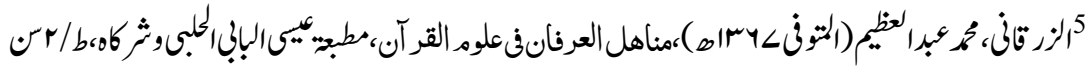

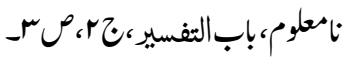

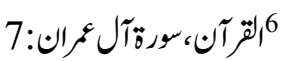

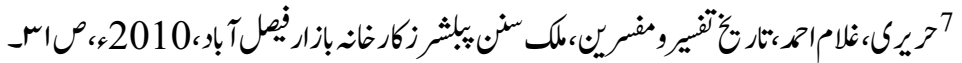

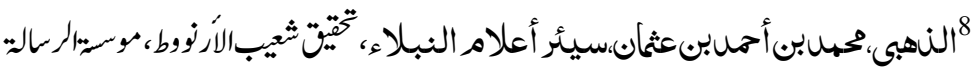

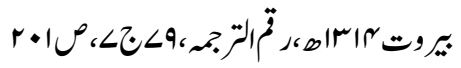

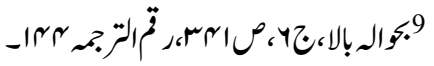




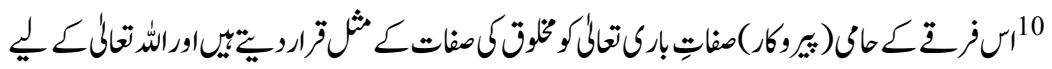

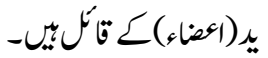

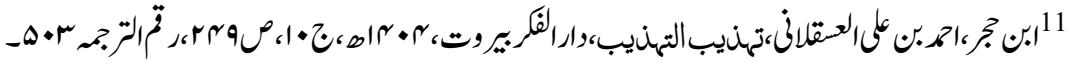

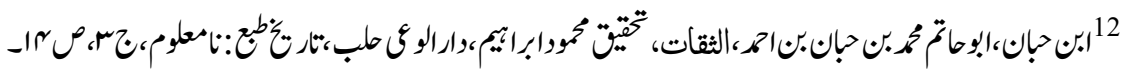

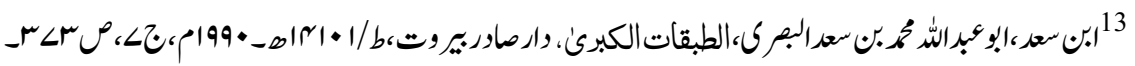

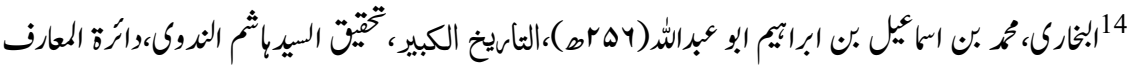

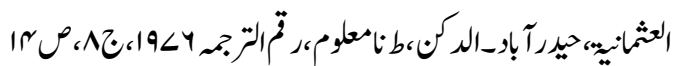

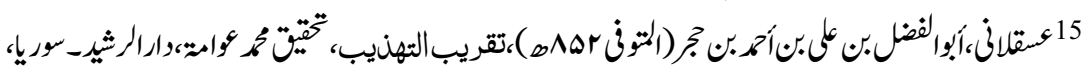
每

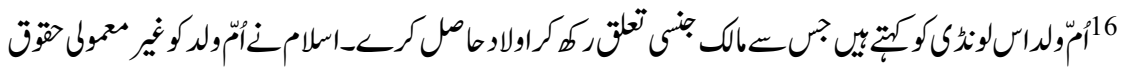

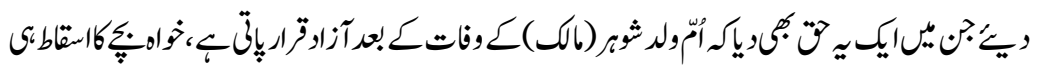

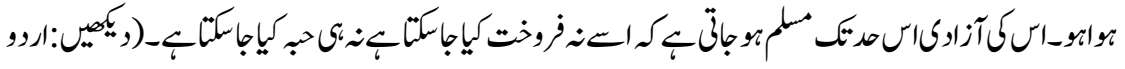

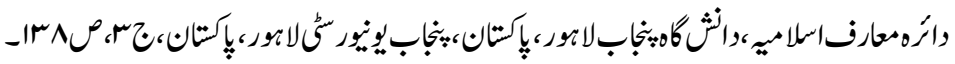

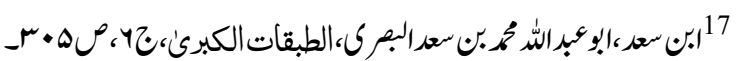

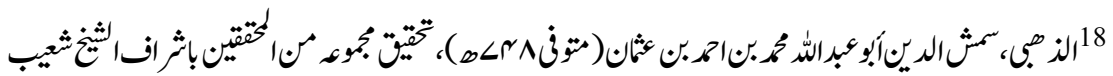

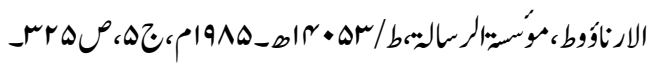

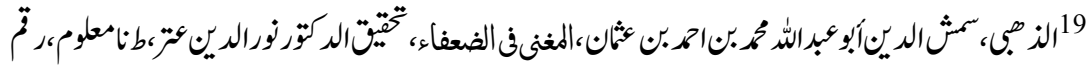

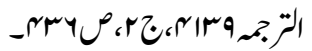

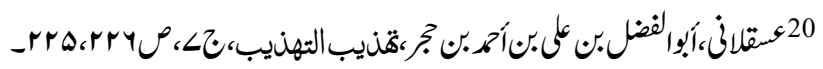

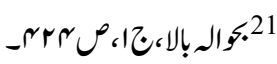
222

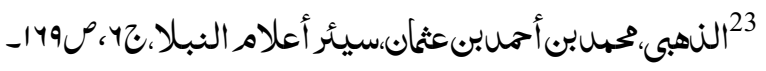
24. 24

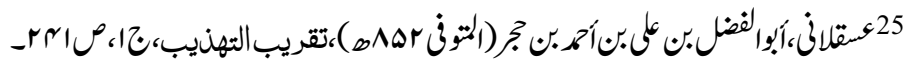

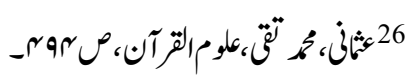

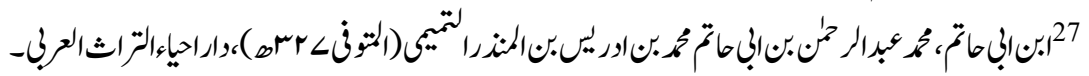

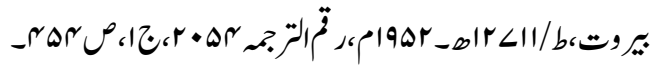




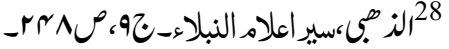

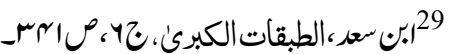

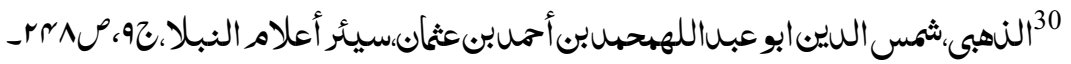

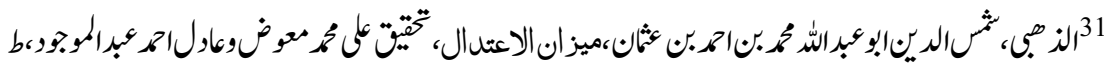

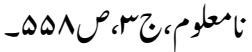
32

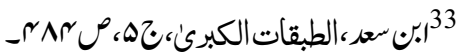

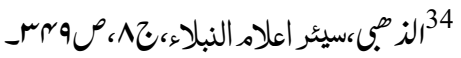

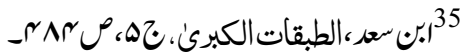

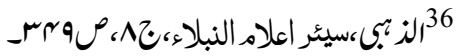

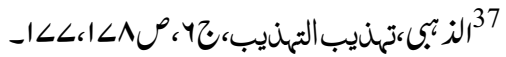

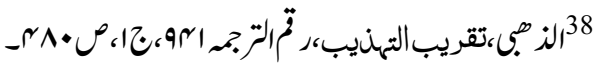

